\title{
'Xiaohe 1': A New Walnut Cultivar with High Fruit Setting Rate of Secondary Bud Germination after the Harm of Late Frost
}

\author{
Jing Wu, Qi He, Caihong Zhang, and Gui Wang \\ Shanxi Academy of Forestry Sciences, Taiyuan, Shanxi 030012, China
}

Additional index words. breeding, late frost hazard, secondary bud germination, walnut

Walnut (Juglans regia L.), a deciduous tree in the Juglandaceae family, is a forest tree species that has a long cultivation history and wide distribution in China because of its economic importance (Pei and $\mathrm{Lu}, 2011$ ). China accounts for more than $50 \%$ of the world's total production of walnuts that are cultivated in more than 30 countries. In China, walnut breeding programs began throughout the country in the mid to late 1960s. In 1990, 32 early fruiting elite walnut cultivars that were public favorites were appraised and selected by the former Ministry of Forestry. Soon after, 'Xiangling', 'Wen 185 ', and series cultivars Liaoning and Zhonglin became the major walnut cultivars in production (NAWI, 2019).

In China, Shanxi Province produces the best-selling walnuts, including 'Fenzhou' and 'Zuoquan Mian' walnuts. The province has a long history of walnut cultivation and is China's major walnut producer ( $\mathrm{Lv}$ et al., 1993).

Since the 1970s, the Shanxi Academy of Forestry has conducted walnut breeding programs and introduced cultivars of foreign origin. More than 10 walnut cultivars have been bred from ecological adaptability trials of cultivars from the United States and Romania.

In recent years, however, late frost or below-freezing temperatures have occurred frequently in early spring in most areas in northern China. In 2006, 2009, 2013, 2015, and 2018, late-frost damage reduced walnut production in the northern region and caused harvest failure in some areas. For example, late frost in 2006 occurred in large areas of

\footnotetext{
Received for publication 3 Sept. 2020. Accepted for publication 7 Oct. 2020.

Published online 9 November 2020.

This work was supported by the Shanxi Forestry Science and Technology Innovation Project (no. 2018LYCX15) and the National Innovation Alliance of Walnut Industry (NAWI).

We thank LetPub (www.letpub.com) for its linguistic assistance during the preparation of this manuscript.

J.W. is the corresponding author. E-mail: wjangel722@ 163.com

This is an open access article distributed under the CC BY-NC-ND license (https://creativecommons. org/licenses/by-nc-nd/4.0/).
}

the Xinjiang Kashgar region, and in the central and southern parts of Shanxi Province it caused freezing damage to walnut trees and decimated production in select areas (Liu et al., 2011; Wang et al., 2007). The damage caused by late frost in 2013 resulted in significant reductions in walnut production in Shaanxi Province, particularly in Weibei region, where walnut yield loss was more than $60 \%$ (Fan et al., 2014). In 2018, a very serious late frost occurred nationwide that caused devastating production losses in most areas (Wang et al., 2020).

To alleviate loss caused by late-frost damage, the Shanxi Academy of Forestry conducted breeding programs for walnut cultivars with resistance to late frost. In Dec. 2019, the Shanxi Provincial Cultivar Certification Committee approved and certified 'Xiaohe 1' as an excellent walnut cultivar with resistance to late-frost temperatures as low as $-6{ }^{\circ} \mathrm{C}$. 'Xiaohe 1 ', with the assigned cultivar number Jin S-SC-JR-004-2019, has high yield, a high fruit set rate after secondary emergence of accessory and other buds, and strong late-frost resistance. The average single-fruit weight of 'Xiaohe 1'is 12.0 to $15.5 \mathrm{~g}$, the shell thickness is $1.22 \mathrm{~mm}$, the suture line is tight, and the kernel yield is $59.54 \%$. The kernel color is light, the quality is good, and the flavor is sweet.

\section{Origin}

'Xiaohe 1' originated from a clone of a bud sport of 'Liaoning 1', which is a cultivar bred through hybridization by the Liaoning Institute of Economic Forestry (Zhao et al., 2020). During the 2007 regional experiments arranged under China's Eleventh Five-Year Plan, scions of the clone were top-grafted into the Fenyang Walnut Test Base in Shanxi Province. The grafts exhibited high yield and excellent nut traits.

Since the discovery of the bud sport in 2007, the clone was appraised, investigated, reproduced, and eventually compared with and evaluated side-by-side with other walnut cultivars. In 2013, the scions collected from Fenyang were grafted into existing walnut trees in Xiaoyi City. Scions of 'Liaoning 1' and 'Luguang', the main walnut cultivars in Shanxi Province, were also grafted because of their superior characteristics of early bear- ing, androgenic type, and high yield, which are similar to the characteristics of 'Xiaohe 1 '.

The cultivar Xiaohe 1 presented highyielding potential despite late-frost incidents after the initial budding. For example, after a province-wide late-frost incident in 2018, the cultivar Xiaohe 1 showed stronger resistance to below-freezing temperature, a higher fruit set rate after secondary emergence of accessory and other buds, and better overall traits than the control cultivars Liaoning 1 and Luguang.

\section{Description and Performance}

The tree stand of 'Xiaohe 1' is semidwarf, with a spreading growth habit and moderate growth rate. The height of a 6year-old tree is four-fifths that of 'Liaoning 1'. The fruit branches are short and thick, with an average length of $16.4 \mathrm{~cm}$ and an average diameter of $0.9 \mathrm{~cm}$. Male flowers open 7 to $10 \mathrm{~d}$ before female flowers. It has high yield potential; a 7-year-old tree can yield $1583.6 \mathrm{~kg} \cdot \mathrm{ha}^{-1}$ during normal years with no late-frost incidents. The secondary and tertiary lateral fruiting branches contribute $\approx 70 \%$ of the total yield. The average fruit set rate of each branch is 1.61 . The projected kernel yield of crown area is 0.33 $\mathrm{kg} \cdot \mathrm{m}^{-2}$

Recently, 'Xiaohe 1' showed high resistance to late frost. In Apr. 2018, during the Qingming Festival, the walnut trees experienced severe late-frost damage at belowfreezing temperatures as low as $-6{ }^{\circ} \mathrm{C}$. Nevertheless, the fruit set rate after the emergence of accessory buds of 'Xiaohe 1' was 1.8-times higher than those of the control cultivars, whereas other cultivars, including Zhonglin 1, Liaoning 1, and Luguang, rarely set fruits (Figs. 1 and 2).

For example, in the Luliang region, the buds of 'Xiaohe 1' sprout in early April, and flowers fully bloom in late April. The male flowers fully bloom in mid-April and open $10 \mathrm{~d}$ earlier than the female flowers. The walnut fruits ripen in early September, and leaves fall in early November. In recent years, phonological events of all cultivars started earlier (Fig. 3) because of early warm temperatures in early spring.

The nut shape of 'Xiaohe 1 ' is nearly round. The average weight of a single nut is between 12.0 and $15.5 \mathrm{~g}$. The shell thickness is $1.22 \mathrm{~mm}$, with a smooth outer surface. The average three-dimensional kernel diameter is $3.58 \mathrm{~cm}$. The whole kernel is easy to remove and the suture is tight. The kernels are resistant to mechanical injury during the collecting, peeling, and drying processes. The kernel comprises $59.54 \%$ of the nut weight. Kernels contain $60.40 \%$ crude fat, $15.93 \%$ crude protein, and $8.39 \%$ sugar. The kernels have a light color, excellent quality, sweet flavor, and fragrant scent (Fig. 4).

To comprehensively evaluate the yield, adaptability, growth, and fruiting characteristics of the cultivar Xiaohe 1, regional tests were conducted in four locations in Shanxi 

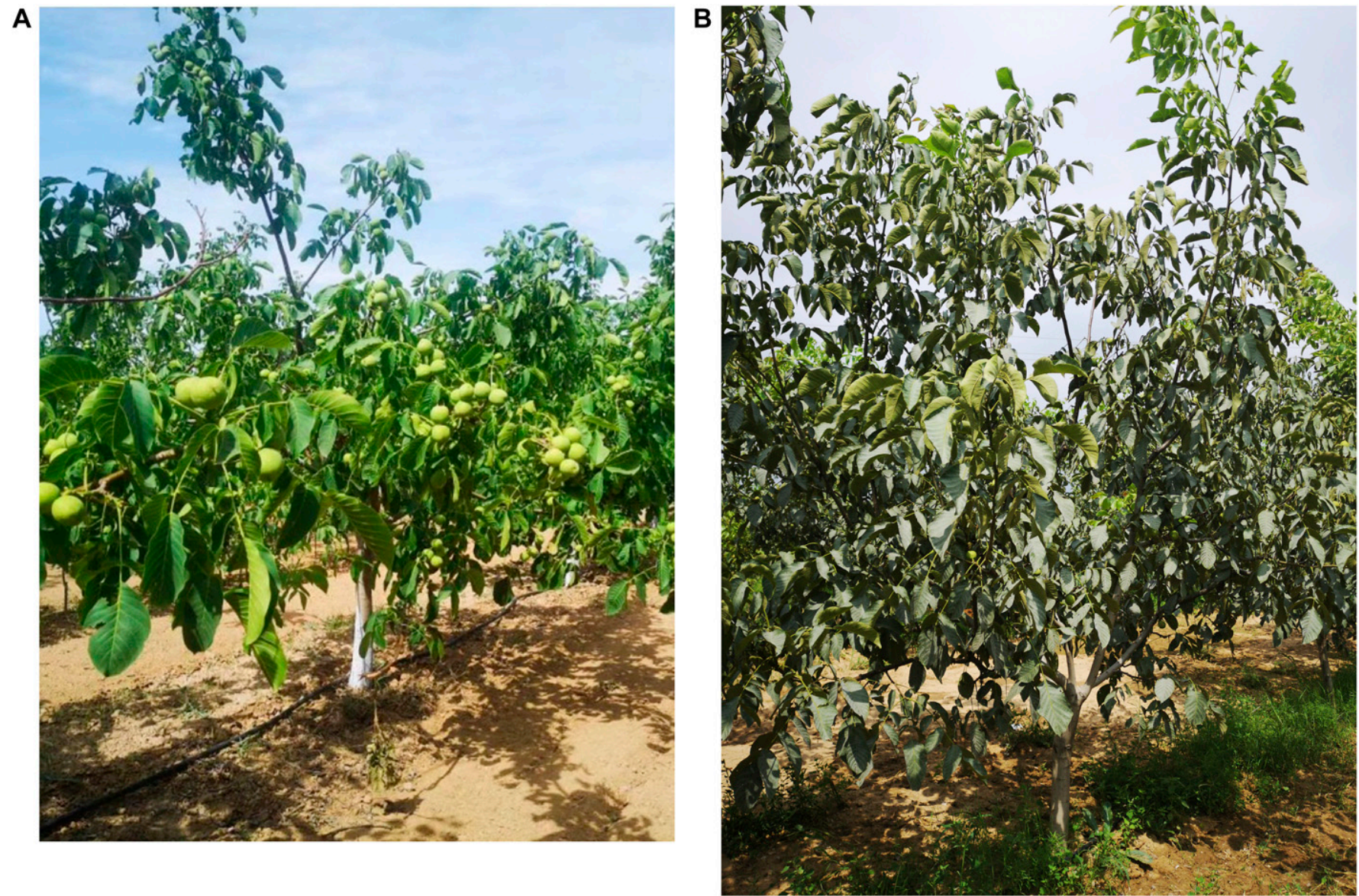

Fig. 1. Eight-year-old 'Xiaohe 1' (left) and 'Liaoning 1' (right) trees with fruits.

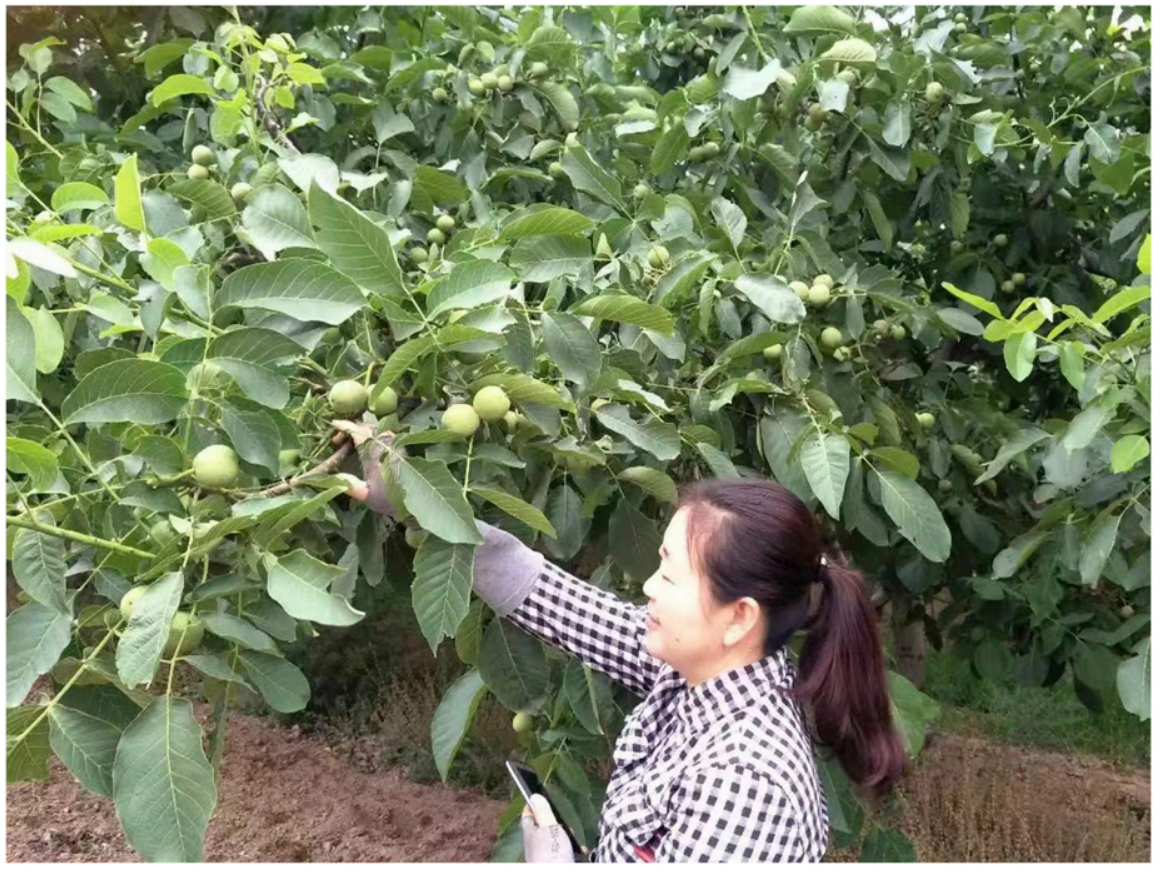

Fig. 2. Thirteen-year-old 'Xiaohe 1' trees with fruit.

Province: Lujiazhuang Village in Fenyang County of Luliang City; Xianzhe Village in Xiaoyi County of Luliang City; Dagou Village in Xinfu County of Xinzhou City; and
Du Village in Anze County of Changzhi City (Table 1).

'Xiaohe 1' walnut trees in all locations grew well, with good tree vigor and steadily increased trunk diameter, tree height, and canopy diameter. The trees set fruits in the second year after grafting and, as expected, there was no significant difference in fruit setting between the locations. The yield per unit projected crown area was between 0.20 and $0.33 \mathrm{~kg} \cdot \mathrm{m}^{-2}$, which exceeded the national standard $\left(0.15 \mathrm{~kg} \cdot \mathrm{m}^{-2}\right)$. The growth and fruiting data of 'Xiaohe 1' in 2019 are shown in Table 2.

From 2016 to 2019, yield per plant and yield per hectare of walnut cultivars Xiaohe 1, Liaoning 1, and Luguang located in Xiaoyi and Fenyang trial sites were recorded and appraised (Tables 3 and 4). Results showed that the yield of three cultivars increased steadily. Notably, the occurrence of late frost in 2018 dramatically reduced the yield of 'Liaoning 1' and 'Luguang' and affected the yield of 'Xiaohe 1' as well. More importantly, and despite the exposure to late frost, Xiaohe 1 has a significantly higher yield than the other two cultivars (Tables 3 and 4).

At the Anze and Xinfu trial sites, scions were grafted in 2015. Yield data available are very variable and not conclusive. However, the trees started producing a small number of fruits in 2017 (second year), had fruiting damage due to late frost in Apr. 2018, and showed promising yields in 2019 .

'Xiaohe 1' has shown strong late-frost resistance based on two incidents of exposure to below-freezing temperatures. During the 


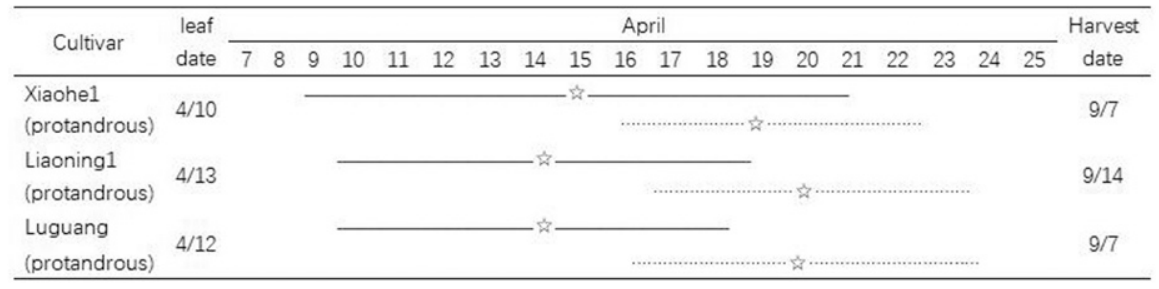

Fig. 3. The leafing dates, pollen-shedding periods, pistillate bloom times, and harvest dates for walnut cultivars Xiaohe 1, Liaoning 1, and Luguang. The straight lines indicate the male flower, the dashed lines indicate the female flower, and the stars are the peak bloom dates.

A

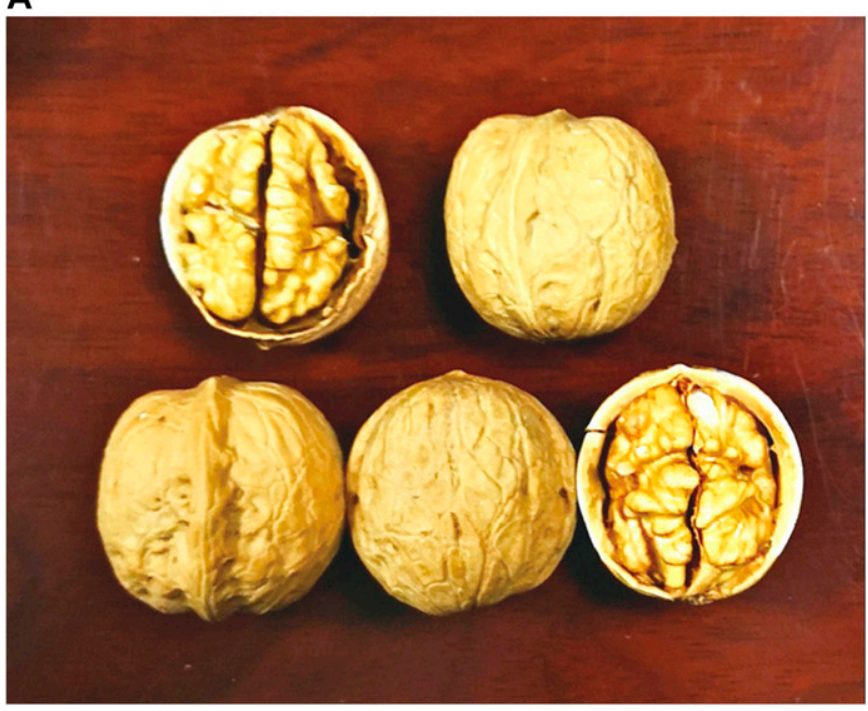

B

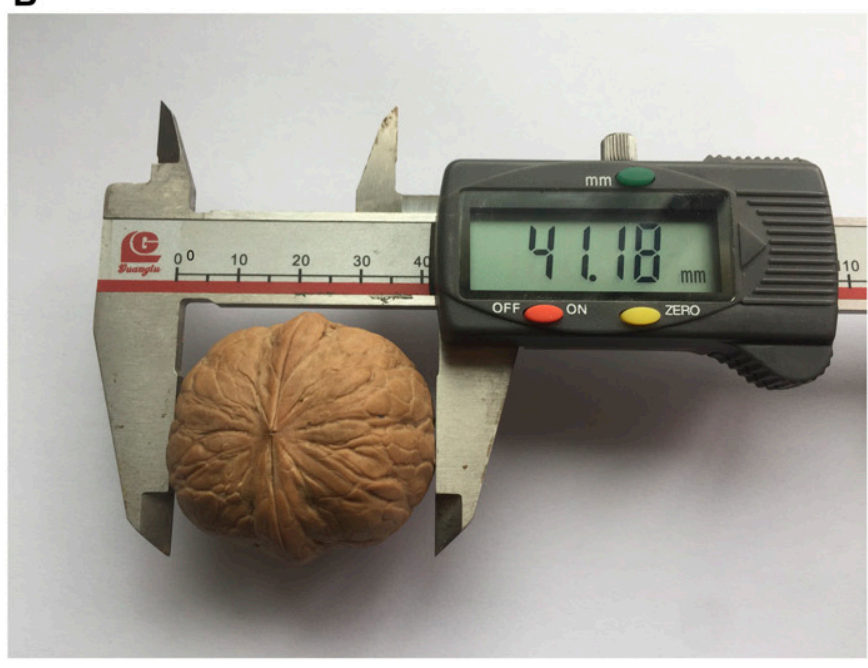

Fig. 4. Kernel nuts of the walnut cultivar Xiaohe 1.

Table 1. Four locations of field trials of walnut cultivars with late-frost resistance inn Shanxi Province, China

\begin{tabular}{lcccc}
\hline Location & Plot area (ha) & Yr & Spacing & Geolocation \\
\hline Fenyang & 0.7 & 2007 (grafting) & $4 \mathrm{~m} \times 3 \mathrm{~m}$ & $\mathrm{~N} 37^{\circ} 15^{\prime}, \mathrm{E} 111^{\circ} 42^{\prime}$ \\
Xiaoyi & 8 & 2013 (grafting) & $4 \mathrm{~m} \times 6 \mathrm{~m}$ & $\mathrm{~N} 37^{\circ} 08^{\prime}, \mathrm{E} 111^{\circ} 38^{\prime}$ \\
Xinfu & 0.3 & 2015 & $4 \mathrm{~m} \times 5 \mathrm{~m}$ & $\mathrm{~N} 38^{\circ} 21^{\prime}, \mathrm{E} 112^{\circ} 31^{\prime}$ \\
Anze & 0.3 & 2015 & $4 \mathrm{~m} \times 5 \mathrm{~m}$ & $\mathrm{~N} 36^{\circ} 02^{\prime}, \mathrm{E} 112^{\circ} 22^{\prime}$ \\
\hline
\end{tabular}

Table 2. Growth profiles of three walnut cultivars in the four locations in 2019.

\begin{tabular}{|c|c|c|c|c|c|c|c|}
\hline \multicolumn{2}{|c|}{ Location } & $\begin{array}{l}\text { Trunk diam } \\
(\mathrm{cm})^{\mathrm{z}}\end{array}$ & $\begin{array}{c}\text { Tree } \\
\text { ht }(\mathrm{m})\end{array}$ & $\begin{array}{c}\text { Canopy } \\
\text { diam }(m)\end{array}$ & $\begin{array}{c}\text { Avg percentage of } \\
\text { fruiting branches }(\%)\end{array}$ & $\begin{array}{l}\text { Avg fruits per } \\
\text { fruiting branch }\end{array}$ & Tree vigor \\
\hline & Liaoning 1 & 23.0 & 4.1 & $3.5 \times 3.6$ & 55.2 & 1.3 & Strong \\
\hline & Luguang & 22.9 & 4.5 & $3.4 \times 3.4$ & 51.1 & 1.4 & Strong \\
\hline & Liaoning 1 & 9.5 & 3.3 & $3.1 \times 3.0$ & 51.7 & 1.1 & Strong \\
\hline & Luguang & 10.0 & 3.4 & $2.9 \times 3.0$ & 50.8 & 1.1 & Strong \\
\hline Xinfu & Xiaohe 1 & 7.9 & 2.1 & $1.9 \times 2.1$ & 60.9 & 1.6 & Strong \\
\hline \multirow{2}{*}{ Anze } & Liaoning 1 & 8.2 & 2.9 & $1.9 \times 2.3$ & 58.2 & 1.4 & Strong \\
\hline & Luguang & 8.3 & 2.8 & $1.9 \times 2.0$ & 50.1 & 1.4 & Strong \\
\hline
\end{tabular}

${ }^{\mathrm{z}}$ The data shown are the mean value. 
Table 3. Yield of three walnut cultivars over the years in Xiaoyi County.

\begin{tabular}{|c|c|c|c|c|}
\hline \multirow[b]{2}{*}{ Cultivar } & \multicolumn{4}{|c|}{ Yield $\left(\mathrm{kg} \cdot \mathrm{ha}^{-1}\right)^{\mathrm{z}}$} \\
\hline & 2016 (fourth yr) & 2017 (fifth yr) & 2018 (sixth yr) & 2019 (seventh yr) \\
\hline Liaoning 1 & $328.1 \pm 56.7 \mathrm{a}$ & $421.2 \pm 97.2 \mathrm{~b}$ & $668.3 \pm 89.1 \mathrm{~b}$ & $800.6 \pm 172.1 \mathrm{~b}$ \\
\hline
\end{tabular}

${ }^{\mathrm{z}}$ Based on 420 trees/ha. The data shown are the mean \pm SE.

${ }^{\mathrm{y}}$ Means within a column followed by different letters are significantly different $(P<0.05)$ according to the least significance test.

Table 4. Yield of three walnut cultivars over the years in Fenyang County.

\begin{tabular}{lcccc}
\hline & \multicolumn{4}{c}{ Yield $\left({\left.\mathrm{kg} \cdot h \mathrm{~h}^{-1}\right)^{\mathrm{z}}}\right.$} \\
\cline { 2 - 5 } Cultivar & $2016(10$ th yr) & $2017(11$ th yr) & $2018(12$ th yr $)$ & 2019 (13th yr) \\
Xiaohe 1 & $3859.0 \pm 416.3 \mathrm{a}^{\mathrm{y}}$ & $4089.7 \pm 540.1 \mathrm{a}$ & $3135.0 \pm 218.3 \mathrm{a}$ & \\
Liaoning 1 & $3162.5 \pm 497.3 \mathrm{a}$ & $3327.7 \pm 207.9 \mathrm{a}$ & $1980.0 \pm 412.5 \mathrm{~b}$ & \\
Luguang & $3465.0 \pm 297.5 \mathrm{a}$ & $3795.3 \pm 501.7 \mathrm{a}$ & $1760.0 \pm 343.5 \mathrm{~b}$ & \\
\hline
\end{tabular}

${ }^{\mathrm{z}}$ Based on 825 trees/ha. The data shown are the mean \pm SE.

${ }^{\mathrm{y}}$ Means within a column followed by different letters are significantly different $(P<0.05)$ according to the least significance test.

Table 5. Survey of accessory buds of walnut cultivars after a severe late-frost event in Apr. 2018 in Xiaoyi County, China.

\begin{tabular}{lcll}
\hline Cultivar & Avg number of sprouted accessory buds & Position of sprouted accessory buds & Avg percentage of fruiting branches from accessory buds (\%) \\
\hline Xiaohe 1 & 4.5 & First to eighth lateral bud & 48.1 \\
Liaoning 1 & 3.0 & First to third lateral bud & 16.6 \\
Luguang & 4.0 & Lower accessory buds (7-10) & 30.0 \\
\hline
\end{tabular}

${ }^{\mathrm{z}}$ The data shown are the mean values.

A

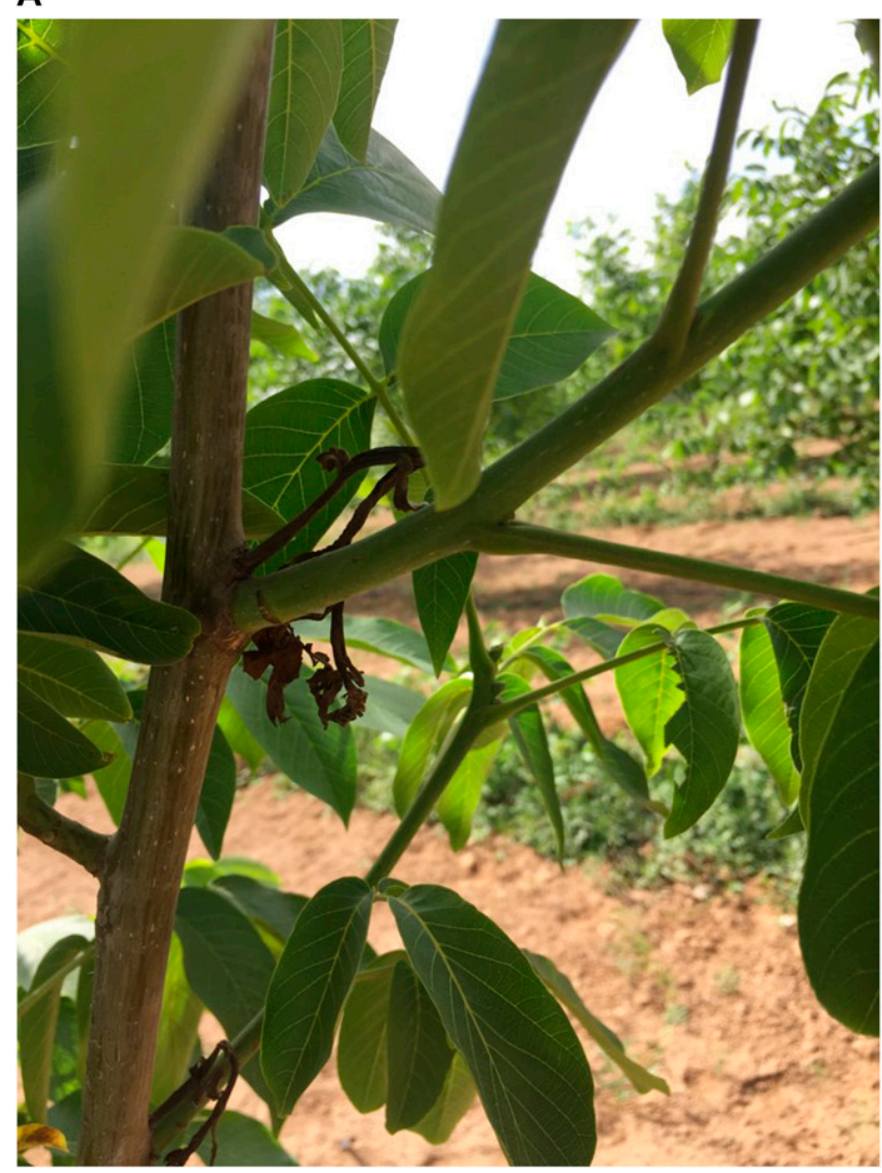

B

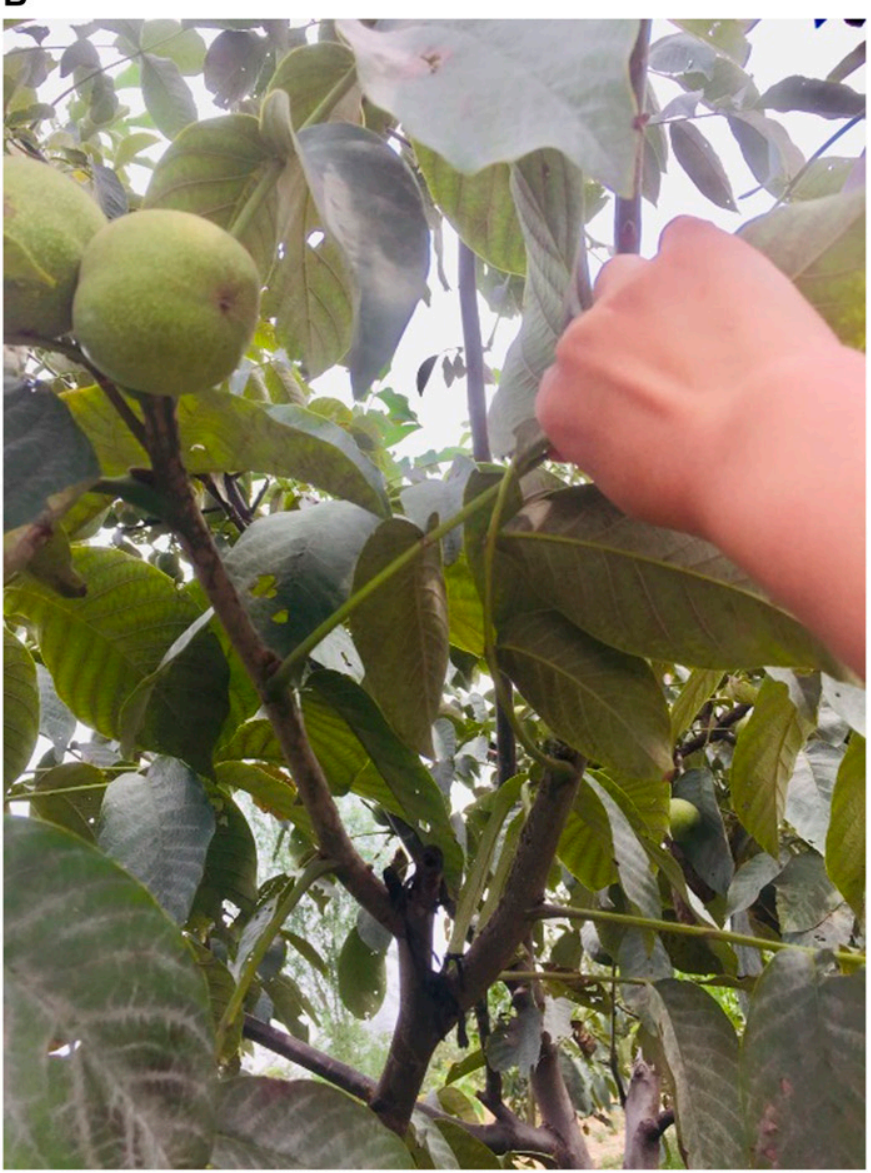

Fig. 5. The accessory buds of 'Xiaohe 1' developed into fruits after the main buds were damaged by late frost in 2018. 
Table 6. Evaluation of late-frost damage in 2009.

\begin{tabular}{lc}
\hline Cultivar & Ratio of affected buds ${ }^{\mathrm{z}}(\%)$ \\
\hline Xiaohe 1 & $<20$ \\
Liaoning 1 & $40-60$ \\
Luguang & 50 \\
\hline
\end{tabular}

${ }^{\mathrm{z}}$ The data shown are the mean values.

2018 Qingming Festival, severe late frost occurred in five provinces in central north China. On 6 Apr., the temperature in Xiaoyi dropped to $-6{ }^{\circ} \mathrm{C}$, and the low temperatures lasted 4 to 5 $\mathrm{d}$. This incident reduced the yield of control cultivars by more than $90 \%$ and caused failed production for some other cultivars. In contrast, 'Xiaohe 1' produced $\approx 70 \%$ (1207 kg.ha ${ }^{-1}$ in 2018 ) of the normal yield (1583 $\mathrm{kg} \cdot \mathrm{ha}^{-1}$ in 2019) because of its good fruit set after the emergence of accessory buds and lower lateral buds. Despite the exposure to below-freezing temperature, 'Xiaohe 1' produced normal-sized fruits. Figure 5 shows the developing fruits from accessory buds after the late frost damaged the main buds. Table 5 shows the data of accessory buds of the three cultivars evaluated. Furthermore, 'Xiaohe 1' showed the lowest rot disease infection rate based on 10 years of investigation in Fenyang. The rot disease infection rate of 'Xiaohe 1' was 5.6\%; however, the infection rate of 'Liaoning 1 ' is $10.8 \%$, and that of 'Luguang' is $8.8 \%$.

Similarly, in 2009, in Shanxi Province, the temperature dropped rapidly on 24 and 25 Mar., with late-frost temperatures of $-2{ }^{\circ} \mathrm{C}$ and $-6{ }^{\circ} \mathrm{C}$ recorded, respectively. This period occurred after buds of all the walnut cultivars started sprouting because of sharp temperature increases to as high as $29^{\circ} \mathrm{C}$ between 15 and 18 Mar. The sprouted buds of all walnut cultivars suffered freezing damage to varying degrees. An assessment of frost resistance of the three cultivars is presented in Table 6.

'Xiaohe 1' has a smooth nutshell surface with a 1.22-mm shell thickness and tight sutures, which make the cultivar suitable for mechanical peeling, cleaning, and processing. The percentage of kernels is high and whole kernels can be removed. The kernels have a light color and sweet flavor. The cultivar has high yield potential and resistance to late frost and below-freezing temperatures $\left(-6{ }^{\circ} \mathrm{C}\right)$. 'Xiaohe 1' can be cultivated in walnutgrowing areas in Shanxi Province and other regions in China that have similar ecological environments. The recommended planting density is 3 to $4 \mathrm{~m} \times 5$ to $6 \mathrm{~m}$ with 'Zha $343^{\prime}$ as the pollinizer cultivar (a variety selected in 1978). The release and utilization of 'Xiaohe 1' may help alleviate the loss in walnut production caused by late-frost occurrences in recent years in northern China.

\section{Literature Cited}

Fan, J., J. Zhang, X. Xu, X. Chen, J. Chen, D. Wang, and J. Feng. 2014. An investigation on frozen damage of walnut trees in Shaanxi Province. J.
Northwest For. Univ. 29(5):120-124, doi: 10.3969/j.issn.1001-7461.2014.05.22.

Liu, D., B. Zhang, S. Peng, H. Zhu, and H. Sun. 2011. Observation on phenological period and varieties choice in avoiding the late frost damage of early-fruiting walnut cultivars. North. Hort. (24):14-17.

Lv, Z., G. Wang, and Z. Gao. 1993. High quality and high yield cultivation techniques of new walnut cultivars. Shanxi University Federation Press, Taiyuan.

National Innovation Alliance of Walnut Industry (NAWI). 2019. White paper on the national innovation alliance of the walnut industry walnut technology in China over the past 70 years. NAWI, Aksu.

Pei, D. and X.Z. Lu. 2011. Walnut germplasm resources in China. China Forestry Publishing House, Beijing.

Wang, Y., Y. Chen, H. Wang, F. Zhu, and Y. Hu. 2020. Research progress on late frost injury of Walnut in China. Agr. Technol. 40(11):49-51, doi: 10.19754/j.nyyjs.20200615015.

Wang, Y., Y. Han, J. Tian, E. Cheng, J. Wang, and $X$. Tian. 2007. Investigation of freezing injury of walnut in early spring in Shanxi Province in 2006. Chin. Fruit (1):53-54, doi: 10.3969/ j.issn.1000-8047.2007.01.025.

Zhao, B., F. Liu, Y. Gong, D. Li, Y. Chang, and Y. Wang. 2020. 'Liaoning 1' walnut cultivar HortScience 55(3):392-394, doi: 10.21273/ hortsci14801-19. 